\title{
Nonpharmacological modulation of dynamic hyperinflation
}

\author{
E.F.M. Wouters
}

\begin{abstract}
Expiratory flow limitation is the pathophysiological hallmark of chronic obstructive pulmonary disease (COPD), but dyspnoea is the most prominent and distressing symptom. Acute dynamic hyperinflation (DH), which refers to the temporary increase in operating lung volumes above their resting value, is a key mechanistic consequence of expiratory flow limitation and has serious mechanical and sensory consequences. In flow-limited patients, pharmacological interventions using bronchodilating agents act by improving dynamic airway function: enhancing lung emptying and reducing lung hyperinflation. Besides bronchodilators, other factors that reduce the ventilatory demand at a given level of exercise or interventions that aim to improve lung emptying or to reduce resting levels of hyperinflation decrease the rate of development of DH in COPD patients. The different nonpharmacological intervention strategies that aim to reduce lung hyperinflation are summarised in the present article, as well as the different underlying mechanisms contributing to lung deflation. The following interventions are systematically reviewed in the present article: breathing supplemental oxygen or low-density gas mixtures of helium and oxygen, pulmonary rehabilitation and noninvasive positive pressure ventilation. Pulmonary rehabilitation and noninvasive pressure ventilation reduce the $\mathrm{DH}$; the effects of heliox-breathing and hyperoxia are more variable. These nonpharmacological interventions have importantly contributed to the present understanding of the role of hyperinflation in COPD patients.
\end{abstract}

KEYWORDS: Chronic obstructive pulmonary disease, heliox breathing, hyperinflation, hyperoxia, noninvasive ventilation, pulmonary rehabilitation

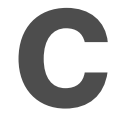
hronic obstructive pulmonary disease (COPD) is characterised by airflow limitation. This reduction in expiratory flow is the pathophysiological hallmark of COPD and is partially reversible with bronchodilation [1]. Flow limitation is the consequence either of an increase in pulmonary compliance or airway resistance. In COPD, lung compliance is increased as a consequence of emphysematous parenchymal destruction with subsequent loss of lung elasticity, which reduces the elastic recoil pressure that is available to drive air out of the lung during expiration. The increase in airway resistance occurs largely due to changes in the smaller conducting airways, which undergo remodelling in response to chronic inflammation [2,3].

As COPD progresses, patients become functionally limited as a result of exertional breathlessness. The pathophysiological mechanisms that contribute to exercise limitation and dyspnoea in COPD are complex and multifactorial, and can be considered as the consequence of abnormalities of the respiratory, cardiovascular, neuromuscular and neurosensory systems.
Detailed physiological studies during exercise in patients with COPD have demonstrated that even in patients with less severe disease, increased ventilatory demands and increasing minute ventilation $\left(V^{\prime} \mathrm{E}\right)$ with exercise can lead to dynamic increases in end-expiratory lung volume (EELV) after expiratory flow limitation (EFL) exceeds a critical level $[4,5]$. This is defined as dynamic hyperinflation (DH): a temporary and variable increase in EELV above its resting value. In flow-limited patients, EELV fluctuates widely between rest and activity, and any increase in ventilation is associated with $\mathrm{DH}$. In advanced COPD, expiratory flows may be significantly limited, even with spontaneous tidal breathing at rest, and lung emptying is incomplete at the end of expiration. To track these changes in EELV, changes in inspiratory capacity (IC) are used based on the assumption that total lung capacity (TLC) does not change appreciably during exercise $[6,7]$.

Therapeutic interventions that reduce or delay the development of lung hyperinflation, either at rest or during exercise, can significantly prolong
CORRESPONDENCE

E.F.M. Wouters

Dept of Respiratory Medicine University Hospital Maastricht P.0. Box 5800 6202 AZ Maastricht The Netherlands Fax: 31433875051 E-mail: e.wouters@lung.azm.nl 
exercise tolerance and reduce exertional breathlessness in patients with COPD.

Bronchodilators are the first-line pharmacological therapy for symptomatic patients with COPD. They act to improve dynamic small airway function and facilitate lung emptying. These effects may be evident even at rest in flow-limited patients, with a reduction in resting EELV and a corresponding increase in IC in response to bronchodilators [8, 9]. The increase in IC in response to bronchodilation means that tidal breathing is positioned over the steeper portion of the pressure-volume curve. Consequently, the efficiency of the ventilatory pump will be improved and oxygen cost of breathing will be reduced. Significant relationships exist between bronchodilation, reduction in operating lung volumes, symptom improvement during exercise and exercise tolerance [10-12].

Besides pharmacological interventions with bronchodilators, factors that reduce the ventilatory demand at a given level of exercise or interventions that aim to improve lung emptying or to reduce resting levels of hyperinflation decrease the rate of development of DH. This delays the onset of critical mechanical limitations that contribute to exercise curtailment, thereby allowing patients to achieve higher levels of exercise within the constraints of their pre-existing EFL. These nonpharmacological interventions modulating $\mathrm{DH}$ will be discussed in more detail.

\section{THE EFFECTS OF OXYGEN ON DH}

Despite the widespread use of oxygen in the treatment of cardiorespiratory disorders associated with hypoxaemia, the effects of oxygen on respiratory mechanics under resting conditions, during exercise and after exercise recovery are more scarcely documented. Oxygen therapy has been shown to reduce exertional breathlessness and improve exercise tolerance in COPD patients; however, responses to this intervention are highly variable and are unpredictable in any given individual [13-19]. These responses to oxygen therapy in patients with chronic airflow limitation cannot be predicted from baseline pulmonary function and gas exchange measurements [14, 19, 20], suggesting that oxygen-dependent factors are instrumental in contributing to exertional symptoms and exercise limitation.

SWINBURN et al. [21], who administered $28 \%$ oxygen through a face mask for $10 \mathrm{~min}$ to 12 hypoxaemic COPD patients, reported a significant decrease in both severity of dyspnoea and $V^{\prime} \mathrm{E}$. This improvement in dyspnoea was generally attributed to a reduction in the hypoxic drive to breathing. O'DONNELL et al. [22] analysed factors contributing to relief of exertional breathlessness during hyperoxia in mildly hypoxaemic patients with chronic airflow limitation. O'DONNELL et al. [22] reported that breathing $60 \%$ oxygen did indeed significantly reduce the intensity of exertional breathlessness and leg effort, and improved exercise endurance compared with room air. Breathlessness fell in direct proportion to the reduction in ventilation, indicating that breathlessness was not diminished at any given level of ventilation during hyperoxia. The fall in $V^{\prime} \mathrm{E}$ during hyperoxia was strongly correlated with the fall in blood lactate without changes in the $V^{\prime} \mathrm{E}$-lactate slopes. Reduced EELV was not shown to contribute to improved breathlessness in this study. Based on these results, O'DONNELL et al. [22] concluded that the improvement in exertional breathlessness is multifactorial but occurs in proportion to the decrease in ventilation, which in turn reflects improved aerobic metabolism at the peripheral muscle level. The same authors further elaborated these findings and analysed the effects of hyperoxia on ventilatory limitation during exercise in a group of patients with COPD whose exercise was limited primarily by ventilatory insufficiency. In another study, O'DONNELL et al. [23] confirmed that oxygen therapy resulted in a reduction in submaximal ventilation and that this reduction in ventilation was strongly correlated with a simultaneous reduction in carbon dioxide production $\left(V^{\prime} \mathrm{CO}_{2}\right)$, indicating that oxygen breathing delayed metabolic acidaemia. Along with the decrease in ventilation during oxygen, there was an increase in IC and inspiratory reserve volume (IRV) at rest and throughout exercise. At isotime during exercise with oxygen, there was also a significant reduction in the extent of $\mathrm{DH}_{\text {; }}$ the fall in hyperinflation was best predicted by the combination of increase in resting IRV and a decrease in isotime breathing frequency. The increase in IRV at rest occurred, in part, as a result of associated reductions in resting $V^{\prime} \mathrm{CO}_{2}$ and, in turn, $V^{\prime}$ E. Oxygen breathing therefore resulted in a delay in $\mathrm{DH}$ during exercise. It is noteworthy from the wide spectrum of responses to hyperoxia among the carefully selected subjects of the study of O'DONNELL et al. [23] that patients with the greatest response to oxygen were those with the largest reserves for tidal volume $(V \mathrm{~T})$ and flow generation at baseline and were those who had the greatest reductions in $V^{\prime} E$-time and lactate-time slopes during oxygen. Interestingly, of the patients who stopped exercise because of dyspnoea during both room air breathing and oxygen tests, there were no changes in peak measurements of ventilation, operational lung volumes or breathing pattern [23].

ALVISI et al. [24] demonstrated that in patients with chronic airflow limitation receiving long-term domiciliary oxygen for severe hypoxaemia, hyperoxic breathing at rest induced a significant reduction of ventilation and $\mathrm{DH}$ with concurrent improvement of the dyspnoea sensation. During 30\% oxygen breathing, there was a significant reduction of $V^{\prime} \mathrm{E}$ and $V \mathrm{~T}$, and a concurrent increase of IC. ALVISI et al. [24] confirmed earlier data [25] that the decrease of $V^{\prime} E$ was due entirely to a drop in $V \mathrm{~T} /$ inspiratory time $(t \mathrm{I})$ ratio while the $t \mathrm{I} /$ total breathing cycle duration remained unchanged. These data suggest that hyperoxic breathing reduces ventilation through a reduction in mean inspiratory flow, while respiratory timing remains constant. The improvement in IC was explained by the decrease in $V$ T without a change in expiratory time, allowing the respiratory system to deflate to a lower end-expiratory volume.

The combined physiological effects of bronchodilators and hyperoxia on exertional dyspnoea were recently studied in normoxic COPD patients [26]. PETERS et al. [26] reported that breathing $50 \%$ oxygen was associated with reduced $V^{\prime} \mathrm{E}$ as a result of reduced breathing frequency, with minimal change in $V \mathrm{~T}$ or IC. Reduced frequency reflected prolongation of both $t \mathrm{I}$ and expiratory time but correlated most closely with the increase in $t$. There was no change in the inspiratory duty 
cycle. In accordance with the results of previous data of the research group, only seven out of the 16 patients studied had reduced operating lung volumes in response to hyperoxic breathing $[22,26]$.

The physiological interactions of the combined intervention of bronchodilation and oxygen breathing resulted in additive effects on exertional dyspnoea and exercise endurance time. However, the net effect of the combination on exercise $V^{\prime} E$ was neutral: the decrease in $V^{\prime} \mathrm{E}$ as a result of decreased breathing frequency during hyperoxia was counterbalanced by the increase in $V^{\prime} \mathrm{E}$ as a result of increased $V \mathrm{~T}$ secondary to bronchodilation [26].

SOMFAY et al. [27] analysed the dose dependence of oxygen administration on $\mathrm{DH}$ in nonhypoxaemic COPD patients. The time course of dynamic changes in operational lung volumes was evaluated throughout constant work-rate exercise while breathing different oxygen concentrations. In the COPD patients, 30\% oxygen significantly decreased both the EELV and end-inspiratory lung volume (EILV), with an additional mild decrease with $50 \%$ oxygen; higher oxygen concentrations did not cause further decreases in lung volumes. Thirty per cent oxygen breathing also decreased the $V^{\prime} \mathrm{E}$ and respiratory rate significantly, with an additional milder drop in breathing frequency with $50 \%$ oxygen. At isotime of the constant workrate exercise tests, oxygen breathing was associated with a doubling of IRV, as VT did not change. SOMFAY et al. [27] postulated that this leads to decreased encroachment on the flat portion of the pressure-volume relationship and thereby to a substantially reduced work of breathing. The plateauing in the dose-response relationship was related to the plateauing in receptor responsiveness at higher oxygen concentrations [27].

Recent studies analysed the effects of oxygen on recovery from exercise in patients with COPD: in daily clinical practice, oxygen is widely used to control acute dyspnoea and to help breathlessness resolve more rapidly. These reports concluded that oxygen after exercise has no influence on the rate of symptomatic recovery [28-30].

Although supplementary oxygen does reduce $\mathrm{DH}$ more rapidly than breathing room air after exercise stops, this improvement in respiratory mechanics neither translates into a significant reduction in the degree of dyspnoea at any time after exercise nor influences the rate at which symptoms resolve [30].

Based on the previously reported studies, it can be concluded that hyperoxia resulted in an attendant reduction in ventilation during exercise and that this reduced ventilation is linked to reduced metabolic acidosis. The effects of hyperoxia on $\mathrm{DH}$ are manifested by a considerable interpatient variability with reduction of hyperinflation in a subset of patients, characterised by greater baseline airway obstruction, greater ventilatory constraints during exercise and poorer exercise performance with steeper dyspnoea/ $V^{\prime}$ E slopes [26].

\section{THE EFFECTS OF REHABILITATION ON DH}

The goals of pulmonary rehabilitation programmes are to reduce symptoms, improve activity and daily function, and restore the highest level of independent function in patients with respiratory diseases [31]. Pulmonary rehabilitation is generally considered as an evidence-based intervention to improve exercise performance and to reduce symptoms of dyspnoea [32].

Improvements of exercise tolerance have been estimated from incremental exercise tests, constant work-rate tests or free-walk testing. In incremental exercise tests, improvements in peak work-rate, as well as in peak oxygen uptake, have been reported [33-36]. The pooled effect size of all randomised controlled studies of the results of pulmonary rehabilitation on the 6-min walk distance is $49 \mathrm{~m}$ [33]. Different studies have reported significant changes in endurance exercise time after pulmonary rehabilitation [36-40].

Recently, PORSZASz et al. [41] demonstrated that after exercise training there is a marked increase in constant work endurance associated with reduced $\mathrm{DH}$ in the majority of subjects. This reduction in $\mathrm{DH}$ was shown to be correlated with a reduced breathing frequency, indicating that a decrease in breathing frequency through exercise training reduces and delays the development of DH. Interestingly, this decrease in breathing frequency was significant at isotime but disappears at the end of exercise. Based on these data, it can be concluded that decreased DH may, in part, mediate the improvement in exercise endurance by delaying the attainment of a critically high inspiratory lung volume [41].

Respiratory muscle training can be part of the pulmonary rehabilitation programme. It would be particularly interesting to distinguish the effects of training on the intrinsic strength and endurance of the respiratory muscles from changes in the breathing pattern adopted in response to loading. In a study evaluating the feasibility of high-intensity respiratory muscle training in moderate-to-severe COPD, it was found that respiratory muscle strength, as well as muscle endurance, significantly improved [42]. In the same study, it was reported that following training, equivalent workloads were achieved with higher $V \mathrm{~T}$ and lower respiratory frequency without changes in $V^{\prime} \mathrm{E}$. The fall in respiratory frequency was a consequence of increased expiratory time, as $t \mathrm{I}$ was unchanged. The increased $V \mathrm{~T}$ was achieved by an increase in mean inspiratory flow. However, EELV remained close to resting functional residual capacity (FRC) and did not change through respiratory muscle training [42].

\section{HELIOX BREATHING AND DH IN COPD}

The use of helium-oxygen mixtures (usually $80 \%$ helium and $20 \%$ oxygen, also called heliox) for the treatment of COPD was introduced in 1935 by BARACH [43]. Maximal flow carried through the airways is determined by their size and compliance at the choke point, as well as by physical gas properties [44]. The density of heliox mixture is about onethird of that of air, while heliox is 1.13 times as viscous as air. This kinematic viscosity (viscosity/density) of the gas mixture is determined for the distribution of turbulence and hence respiratory resistance when factors other than the physical properties of the inspired gas remain unchanged [45]. The tendency for turbulence is related to the linear velocity, to the diameter of the tube and to the density of the gas mixture. In COPD patients who exhibit tidal EFL and $\mathrm{DH}$ at rest, heliox breathing would be expected to increase maximal expiratory flow (MEF) with a concomitant decrease of $\mathrm{DH}$ if the 
flow-limiting segment is located in the central airways. In contrast, if the flow-limiting segment is located in the peripheral airways, the viscous flow-limiting mechanism should prevail as a consequence of the laminar flow regimen in these smaller airways based on Reynolds' number [46, 47]. The comparison of MEF-volume curves while breathing air and heliox was originally used as a test for the early detection of peripheral airway obstruction [48]. Controversial effects of heliox breathing have previously been reported on respiratory resistance [46, 49].

Also controversial is the effect of heliox breathing on $\mathrm{DH}$. Some authors found no significant reduction in FRC with heliox, while others reported either a substantial fall in FRC [50] or a reduction in EELV without a significant increment in EILV and increases in maximal $V^{\prime}$ E during heliox breathing [51].

PECCHIARI et al. [52] studied the effects of heliox breathing on $\mathrm{DH}$ in COPD patients, classified as flow limited and non-flow limited based on the outcome of negative expiratory pressure (NEP) application. Patients were classified as either non-flow limited if the application of NEP increased expiratory flow over the entire range of the control $V \mathrm{~T}$ or flow limited if the control and test expiratory flow-volume loops were superimposed. PECCHIARI et al. [52] reported that heliox had no effect on $\mathrm{DH}$ in all COPD patients who were flow limited while breathing air at rest, independent of posture. Heliox breathing did not change the breathing pattern in these patients. Breathing pattern was changed only in patients who were non-flow limited while breathing air and whose heliox expiratory flows with NEP were higher while breathing heliox than while breathing air, reflecting a density-dependent decrease in airway resistance [52]. The absence of effects of heliox breathing in the flow-limited patients indicates that the flow-limiting segment is located in peripheral airways, where flow is limited by the viscous mechanism and MEF is independent of gas density. These data fit with previously reported data of the effects of heliox breathing on the impedance spectrum of the respiratory system in COPD [46].

The effect of heliox on lung hyperinflation, dyspnoea and exercise endurance capacity was recently reported [53]. At rest, heliox breathing did not induce significant changes in lung mechanics and gas-exchange variables, with the exception of a small increase in the forced expiratory volume in one second. However, mean exercise duration increased significantly during heliox breathing versus air. At isotime, this was associated with a significant increase in IC, IRV and IC/ $V^{\prime} \mathrm{E}$, and, even at peak exercise, $V \mathrm{~T}, \mathrm{IC}, \mathrm{MEF}, V^{\prime} \mathrm{E}$ and $V^{\prime} \mathrm{E} / V^{\prime} \mathrm{CO}_{2}$ were significantly higher during heliox than during air breathing. Analysis of operational volumes during exercise revealed a significant reduction in $\mathrm{DH}$ by heliox [53].

In conclusion, it seems that heliox breathing has limited effects on lung volumes under resting conditions, particularly in flowlimited patients. Heliox breathing has the potential to improve high-intensity exercise endurance capacity in moderate-to-severe COPD patients, but further studies are needed to demonstrate this positive outcome in different COPD populations.

\section{NONINVASIVE VENTILATION AND HYPERINFLATION IN COPD}

Noninvasive positive pressure ventilation (NPPV) has attained an important role in the treatment of COPD with acute respiratory failure by avoiding intubation and prolonging survival [54-57]. Controversy remains regarding the effectiveness of long-term home ventilation in patients with hypercapnic but stable COPD [58], and particularly on the mechanisms underlying positive outcomes. The ability of NPPV to reduce hyperinflation was suggested more than a decade ago [59] but has only been investigated more intensely in recent studies.

DiAz et al. [60] studied 36 stable hypercapnic COPD patients in a two-arm, single-blinded, randomised study of active NPPV versus sham NPPV. After a 2-week run-in period, NPPV was applied for $3 \mathrm{~h} \cdot \mathrm{day}^{-1}, 5$ days a week. The authors reported that a high-level inspiratory pressure setting led to significant increases in $V \mathrm{~T}$ and expiratory time, as well as a significant reduction in diaphragmatic loading. The NPPV group exhibited significant reductions in FRC and residual volume (RV), and a mild decrease in TLC, whereas FEV1, forced vital capacity (FVC) and forced mid-expiratory flow increased. After NPPV, RV was reduced more than TLC, resulting in a mean increase in FVC, and FRC was found to be reduced more than TLC, resulting in an increase in IC. Changes in carbon dioxide tension were strongly related to changes in dynamic intrinsic positive end-expiratory pressure, and changes in both parameters were closely related to changes in several lung function parameters, including changes in lung volumes, such as FRC and IC. The study by DIAZ et al. [60] clearly illustrates that short-term application of NPPV to stable hypercapnic patients with COPD decreases lung hyperinflation and that the concomitant reduction of hypercapnia is related to the decrease in lung hyperinflation. The most evident explanation for the significant reduction in lung volumes after NPPV put forward by the authors is the marked increase in expiratory time during NPPV, favouring the emptying of slow lung units. Another explanation for the decrease in lung hyperinflation could be an improvement in airway resistance secondary to a persistent correction of hypoxia, a reduction in airway wall oedema or recruitment of normal lung, previously collapsed by hyperinflated emphysematous areas with a consequent increase in airway tethering [60].

The findings of DIAZ et al. [60] were more recently confirmed by a retrospective explorative study in 46 patients with stable COPD [61]. This study demonstrated that long-term application of NPPV in stable COPD patients resulted in a decreased hyperinflation in terms of a reduction in RV/TLC, thereby improving IC. This reduction in hyperinflation was accompanied by a significant and sustained amelioration of daytime blood gas tensions, and particularly a decrease in carbon dioxide tension [61].

Based on the results of both studies, it can be concluded that in well-characterised COPD patients, NPPV results in reduction in hyperinflation and an increase in IC, and that this deflation may play a central role in the beneficial effects of NPPV in stable COPD.

\section{CONCLUSIONS}

The main consequence of EFL in COPD is lung hyperinflation. During activity, acute-on-chronic hyperinflation has serious sensory and mechanical consequences and is a key concept in activity limitation in COPD. Discovery of this link has developed new physiologically based strategies to reduce 
hyperinflation and improve exercise tolerance for patients with COPD. DH can be reduced either by improving airflow during expiration or by reducing the rate of breathing to increase the time for expiration. Heliox breathing aims to reduce resistance and increase MEF by changing the kinematic viscosity of the inspired gas. Particularly in flow-limited patients, heliox breathing has a limited effect on lung volumes under resting conditions, suggesting that the flow limitation in these patients is largely located in the peripheral airways. Further studies are needed, focusing particularly on the potential of heliox breathing to improve high-intensity exercise endurance capacity, to demonstrate beneficial effects of this costly and cumbersome intervention in COPD patients. Hyperoxia in COPD patients is associated with a fall in ventilation that is strongly correlated with a delayed metabolic acidaemia. However, the effects of hyperoxia on DH show a considerable interpatient variability. Pulmonary rehabilitation reduces $\mathrm{DH}$ by decreasing breathing frequency and delaying the development of DH. Noninvasive pressure ventilation in hypercapnic patients reduces lung hyperinflation, particularly by increasing the expiratory time, thereby favouring the emptying of slow lung units.

This spectrum of nonpharmacological interventions has significantly contributed to a firm understanding of the role of hyperinflation in chronic obstructive pulmonary disease patients. Further studies are needed to confirm current observations in broader groups of chronic obstructive pulmonary disease patients before new strategies can be recommended to improve exercise tolerance in these patients.

\section{REFERENCES}

1 Calverley PM, Koulouris NG. Flow limitation and dynamic hyperinflation: key concepts in modern respiratory physiology. Eur Respir J 2005; 25: 186-199.

2 Hogg JC, Macklem PT, Thurlbeck WM. Site and nature of airway obstruction in chronic obstructive lung disease. $N$ Engl J Med 1968; 278: 1355-1360.

3 Yanai M, Sekizawa K, Ohrui T, et al. Site of airway obstruction in pulmonary disease: direct measurement of intrabronchial pressure. J Appl Physiol 1992; 72: 1016-1023.

4 O'Donnell DE, Bertley JC, Chau LK, et al. Qualitative aspects of exertional breathlessness in chronic airflow limitation: pathophysiologic mechanisms. Am J Respir Crit Care Med 1997; 155: 109-115.

5 O'Donnell DE, Revill SM, Webb KA. Dynamic hyperinflation and exercise intolerance in chronic obstructive pulmonary disease. Am J Respir Crit Care Med 2001; 164: 770-777.

6 Stubbing DG, Pengelly LD, Morse JL, et al. Pulmonary mechanics during exercise in subjects with chronic airflow obstruction. J Appl Physiol 1980; 49: 511-515.

7 Aliverti A, Stevenson N, Dellaca RL, et al. Regional chest wall volumes during exercise in chronic obstructive pulmonary disease. Thorax 2004; 59: 210-216.

8 Tantucci C, Duguet A, Similowski T, et al. Effect of salbutamol on dynamic hyperinflation in chronic obstructive pulmonary disease patients. Eur Respir J 1998; 12: 799-804.
9 Boni E, Corda L, Franchini D, et al. Volume effect and exertional dyspnoea after bronchodilator in patients with COPD with and without expiratory flow limitation at rest. Thorax 2002; 57: 528-532.

10 Belman MJ, Botnick WC, Shin JW. Inhaled bronchodilators reduce dynamic hyperinflation during exercise in patients with chronic obstructive pulmonary disease. Am J Respir Crit Care Med 1996; 153: 967-975.

11 O'Donnell DE, Voduc N, Fitzpatrick M, et al. Effect of salmeterol on the ventilatory response to exercise in chronic obstructive pulmonary disease. Eur Respir J 2004; 24: 86-94.

12 O'Donnell DE, Fluge T, Gerken F, et al. Effects of tiotropium on lung hyperinflation, dyspnoea and exercise tolerance in COPD. Eur Respir J 2004; 23: 832-840.

13 Stein DA, Bradley BL, Miller WC. Mechanisms of oxygen effects on exercise in patients with chronic obstructive pulmonary disease. Chest 1982; 81: 6-10.

14 Bradley BL, Garner AE, Billiu D, et al. Oxygen-assisted exercise in chronic obstructive lung disease. The effect on exercise capacity and arterial blood gas tensions. Am Rev Respir Dis 1978; 118: 239-243.

15 Bye PT, Esau SA, Levy RD, et al. Ventilatory muscle function during exercise in air and oxygen in patients with chronic airflow limitation. Am Rev Respir Dis 1985; 132: 236-240.

16 Dean NC, Brown JK, Himelman RB, et al. Oxygen may improve dyspnea and endurance in patients with chronic obstructive pulmonary disease and only mild hypoxemia. Am Rev Respir Dis 1992; 146: 941-945.

17 Swinburn CR, Wakefield JM, Jones PW. Relationship between ventilation and breathlessness during exercise in chronic obstructive airways disease is not altered by prevention of hypoxaemia. Clin Sci (Lond) 1984; 67: 515-519.

18 Lane R, Cockcroft A, Adams L, et al. Arterial oxygen saturation and breathlessness in patients with chronic obstructive airways disease. Clin Sci (Lond) 1987; 72: 693-698.

19 Woodcock AA, Gross ER, Geddes DM. Oxygen relieves breathlessness in "pink puffers". Lancet 1981; 1: 907-909.

20 Light RW, Mahutte CK, Stansbury DW, et al. Relationship between improvement in exercise performance with supplemental oxygen and hypoxic ventilatory drive in patients with chronic airflow obstruction. Chest 1989; 95: 751-756.

21 Swinburn CR, Mould H, Stone TN, et al. Symptomatic benefit of supplemental oxygen in hypoxaemic patients with chronic lung disease. Am Rev Respir Dis 1991; 143: 913-915.

22 O'Donnell DE, Bain DJ, Webb KA. Factors contributing to relief of exertional breathlessness during hyperoxia in chronic airflow limitation. Am J Respir Crit Care Med 1997; 155: 530-535.

23 O'Donnell DE, D'Arsigny C, Webb KA. Effects of hyperoxia on ventilatory limitation during exercise in advanced chronic obstructive pulmonary disease. Am J Respir Crit Care Med 2001; 163: 892-898.

24 Alvisi V, Mirkovic T, Nesme P, et al. Acute effects of hyperoxia on dyspnea in hypoxemia patients with chronic airway obstruction at rest. Chest 2003; 123: 1038-1046.

25 Sorli J, Grassino A, Lorange G, et al. Control of breathing in patients with chronic obstructive lung disease. Clin Sci Mol Med 1978; 54: 295-304.

26 Peters MM, Webb KA, O'Donnell DE. Combined physiological effects of bronchodilators and hyperoxia on exertional dyspnoea in normoxic COPD. Thorax 2006; 61: 559-567. 
27 Somfay A, Porszasz J, Lee SM, et al. Dose-response effect of oxygen on hyperinflation and exercise endurance in nonhypoxaemic COPD patients. Eur Respir J 2001; 18: 77-84.

28 Nandi K, Smith AA, Crawford A, et al. Oxygen supplementation before or after submaximal exercise in patients with chronic obstructive pulmonary disease. Thorax 2003; 58: 670-673.

29 Lewis CA, Eaton TE, Young P, et al. Short-burst oxygen immediately before and after exercise is ineffective in nonhypoxic COPD patients. Eur Respir J 2003; 22: 584-588.

30 Stevenson NJ, Calverley PM. Effect of oxygen on recovery from maximal exercise in patients with chronic obstructive pulmonary disease. Thorax 2004; 59: 668-672.

31 Nici L, Donner C, Wouters E, et al. American Thoracic Society/European Respiratory Society statement on pulmonary rehabilitation. Am J Respir Crit Care Med 2006; 173: 1390-1413.

32 Pulmonary rehabilitation: joint ACCP/AACVPR evidencebased guidelines. ACCP/AACVPR Pulmonary Rehabilitation Guidelines Panel. American College of Chest Physicians. American Association of Cardiovascular and Pulmonary Rehabilitation. Chest 1997; 112: 1363-1396.

33 Lacasse Y, Brosseau L, Milne S, et al. Pulmonary rehabilitation for chronic obstructive pulmonary disease. Cochrane Database Syst Rev, 2002: CD003793.

34 O'Donnell DE, McGuire M, Samis L, et al. The impact of exercise reconditioning on breathlessness in severe chronic airflow limitation. Am J Respir Crit Care Med 1995; 152: 2005-2013.

35 Reardon J, Awad E, Normandin E, et al. The effect of comprehensive outpatient pulmonary rehabilitation on dyspnea. Chest 1994; 105: 1046-1052.

36 Ries AL, Kaplan RM, Limberg TM, et al. Effects of pulmonary rehabilitation on physiologic and psychosocial outcomes in patients with chronic obstructive pulmonary disease. Ann Intern Med 1995; 122: 823-832.

37 Weiner P, Azgad Y, Ganam R. Inspiratory muscle training combined with general exercise reconditioning in patients with COPD. Chest 1992; 102: 1351-1356.

38 Simpson K, Killian K, McCartney N, et al. Randomised controlled trial of weightlifting exercise in patients with chronic airflow limitation. Thorax 1992; 47: 70-75.

39 Hernandez MT, Rubio TM, Ruiz FO, et al. Results of a home-based training program for patients with COPD. Chest 2000; 118: 106-114.

40 Cambach W, Chadwick-Straver RV, Wagenaar RC, et al. The effects of a community-based pulmonary rehabilitation programme on exercise tolerance and quality of life: a randomized controlled trial. Eur Respir J 1997; 10: 104-113.

41 Porszasz J, Emtner M, Goto S, et al. Exercise training decreases ventilatory requirements and exercise-induced hyperinflation at submaximal intensities in patients with COPD. Chest 2005; 128: 2025-2034.

42 Sturdy G, Hillman D, Green D, et al. Feasibility of highintensity, interval-based respiratory muscle training in COPD. Chest 2003; 123: 142-150.

43 Barach AL. The use of helium in the treatment of asthma and obstructive lesions in the larynx and trachea. Ann Intern Med 1935; 9: 739-765.
44 Dawson SV, Elliott EA. Wave-speed limitation on expiratory flow - a unifying concept. J Appl Physiol 1977; 43: 498-515.

45 Mc IM, Mead J, Selverstone NJ, et al. Measurement of lung tissue viscous resistance using gases of equal kinematic viscosity. J Appl Physiol 1955; 7: 485-490.

46 Wouters EF, Landser FJ, Polko $\mathrm{AH}$, et al. Impedance measurement during air and helium-oxygen breathing before and after salbutamol in COPD patients. Clin Exp Pharmacol Physiol 1992; 19: 95-101.

47 Wilson T, Rodarte J, Butler JP. Wave-speed and viscous flow limitation. Macklem PT, Mead J, eds. Handbook of Physiology: the Respiratory System, vol. III. Baltimore, American Physiological Society, 1986; pp. 55-61.

48 Dosman J, Bode F, Urbanetti J, et al. The use of a heliumoxygen mixture during maximum expiratory flow to demonstrate obstruction in small airways in smokers. J Clin Invest 1975; 55: 1090-1099.

49 Grape B, Channin E, Tyler JM. The effect of helium and oxygen mixtures on pulmonary resistances in emphysema. Am Rev Respir Dis 1960; 81: 823-829.

50 Swidwa DM, Montenegro HD, Goldman MD, et al. Helium-oxygen breathing in severe chronic obstructive pulmonary disease. Chest 1985; 87: 790-795.

51 Babb TG. Ventilatory response to exercise in subjects breathing $\mathrm{CO}_{2}$ or $\mathrm{HeO}_{2}$. J Appl Physiol 1997; 82: 746-754.

52 Pecchiari M, Pelucchi A, D'Angelo E, et al. Effect of heliox breathing on dynamic hyperinflation in COPD patients. Chest 2004; 125: 2075-2082.

53 Palange P, Valli G, Onorati P, et al. Effect of heliox on lung dynamic hyperinflation, dyspnea, and exercise endurance capacity in COPD patients. J Appl Physiol 2004; 97: 1637-1642.

54 Brochard L, Mancebo J, Wysocki M, et al. Noninvasive ventilation for acute exacerbations of chronic obstructive pulmonary disease. N Engl J Med 1995; 333: 817-822.

55 Plant PK, Owen JL, Elliott MW. Early use of non-invasive ventilation for acute exacerbations of chronic obstructive pulmonary disease on general respiratory wards: a multicentre randomised controlled trial. Lancet 2000; 355: 1931-1935.

56 Peter JV, Moran JL, Phillips-Hughes J, et al. Noninvasive ventilation in acute respiratory failure - a meta-analysis update. Crit Care Med 2002; 30: 555-562.

57 Liesching T, Kwok H, Hill NS. Acute applications of noninvasive positive pressure ventilation. Chest 2003; 124: 699-713.

58 Rossi A. Noninvasive ventilation has not been shown to be ineffective in stable COPD. Am J Respir Crit Care Med 2000; 161: 688-689.

59 Elliott MW, Mulvey DA, Moxham J, et al. Domiciliary nocturnal nasal intermittent positive pressure ventilation in COPD: mechanisms underlying changes in arterial blood gas tensions. Eur Respir J 1991; 4: 1044-1052.

60 Diaz O, Begin P, Torrealba B, et al. Effects of noninvasive ventilation on lung hyperinflation in stable hypercapnic COPD. Eur Respir J 2002; 20: 1490-1498.

61 Budweiser S, Heinemann F, Fischer W, et al. Long-term reduction of hyperinflation in stable COPD by noninvasive nocturnal home ventilation. Respir Med 2005; 99: 976-984. 